\section{BRAZIULIAN JOURNAL \\ OF MEDICAL AND BIOLOGICAL RLSF.ARCH}

www.bjournal.com.br
ISSN 0100-879X

Volume 43 (02) 124-225 February 2010

BIOMEDICAL SCIENCES

AND

CLINICAL INVESTIGATION

Braz J Med Biol Res, February 2010, Volume 43(2) 150-159

A bovine herpesvirus 5 recombinant defective in the thymidine kinase (TK) gene and a double mutant lacking TK and the glycoprotein E gene are fully attenuated for rabbits

S.C. Silva, M.C.S. Brum, R. Weiblen, E.F. Flores and S.I. Chowdhury

The Brazilian Journal of Medical and Biological Research is partially financed by
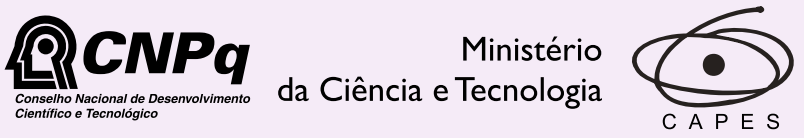

Ministério da Educação

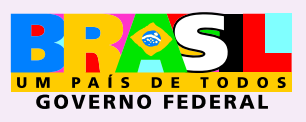

Institutional Sponsors 


\title{
A bovine herpesvirus 5 recombinant defective in the thymidine kinase (TK) gene and a double mutant lacking TK and the glycoprotein E gene are fully attenuated for rabbits
}

\author{
S.C. Silva ${ }^{1}$, M.C.S. Brum ${ }^{1}$, R. Weiblen ${ }^{1}$, E.F. Flores ${ }^{1}$ and S.I. Chowdhury ${ }^{2}$ \\ ${ }^{1}$ Setor de Virologia, Departamento de Microbiologia e Parasitologia and \\ Departamento de Medicina Veterinária Preventiva, \\ Universidade Federal de Santa Maria, Santa Maria, RS, Brasil \\ ${ }^{2}$ Department of Pathobiological Sciences, School of Veterinary Medicine, \\ Louisiana State University, Baton Rouge, LA, USA
}

\begin{abstract}
Bovine herpesvirus 5 (BoHV-5), the agent of herpetic meningoencephalitis in cattle, is an important pathogen of cattle in South America and several efforts have been made to produce safer and more effective vaccines. In the present study, we investigated in rabbits the virulence of three recombinant viruses constructed from a neurovirulent Brazilian BoHV-5 strain (SV507/99). The recombinants are defective in glycoprotein $\mathrm{E}(\mathrm{BoHV}-5 \mathrm{gE} \Delta$ ), thymidine kinase (BoHV-5TK $\Delta$ ) and both proteins (BoHV-5gE $\Delta$ TK $\Delta$ ). Rabbits inoculated with the parental virus $(\mathrm{N}=8)$ developed neurological disease and died or were euthanized in extremis between days 7 and 13 post-infection (pi). Infectivity was detected in several areas of their brains. Three of 8 rabbits inoculated with the recombinant BoHV-5gE $\Delta$ developed neurological signs between days 10 and 15 pi and were also euthanized. A more restricted virus distribution was detected in the brain of these animals. Rabbits inoculated with the recombinants BoHV-5TK $\Delta$ $(\mathrm{N}=8)$ or BoHV-5gE $\Delta \mathrm{TK} \Delta(\mathrm{N}=8)$ remained healthy throughout the experiment in spite of variable levels of virus replication in the nose. Dexamethasone (Dx) administration to rabbits inoculated with the three recombinants at day 42 pi did not result in viral reactivation, as demonstrated by absence of virus shedding and/or increase in virus neutralizing titers. Nevertheless, viral DNA was detected in the trigeminal ganglia or olfactory bulbs of all animals at day 28 post-Dx, demonstrating they were latently infected. These results show that recombinants BoHV-5TK $\Delta$ and BoHV-5gE $\Delta$ TK $\Delta$ are attenuated for rabbits and constitute potential vaccine candidates upon the confirmation of this phenotype in cattle.
\end{abstract}

Key words: BoHV-5; gE and TK deletion mutants; Pathogenesis; Virulence; Vaccine candidate

\section{Introduction}

Bovine herpesvirus type 5 (BoHV-5) is a neurovirulent alpha-herpesvirus associated with meningoencephalitis generally fatal to cattle (1). BoHV-5 infection and disease have been occasionally described in several countries, yet the disease is noticeably more frequent in Brazil and Argentina where outbreaks are reported every year (2-6). BoHV-5 is antigenically and genetically related to bovine herpesvirus 1 (BoHV-1), the agent of respiratory (infectious bovine rhinotracheitis) and genital disease in cattle (infectious pustular vulvovaginitis/balanoposthitis) (1). These viruses belong to the family Herpesviridae, subfamily Alphaherpesvirinae, genus Varicellavirus $(7,8)$. The BoHV-1 and BoHV-5 genomes display the same genomic organization, share a nucleotide homology of approximately $85 \%$ and a similarity of $82 \%$ at the protein level (8). The major biological difference between these viruses seems to be the neurovirulent potential: BoHV-5 is highly neurovirulent for the natural hosts and for experimental animals (9), whereas BoHV-1 is far less neurovirulent and only occasionally has been associated with neurological infection (2). Like other alpha-herpesviruses, BoHV-5 and BoHV-1 establish lifelong latent infection in sensory nerve ganglia $(9,10)$.

The BoHV-5 genome consists of a linear double-stranded DNA molecule of approximately $138 \mathrm{~kb}$ in length and encodes

Correspondence: E.F. Flores, Departamento de Medicina Veterinária Preventiva, Centro de Ciências Rurais, Universidade Federal de Santa Maria, 97105-900 Santa Maria, RS, Brasil. Fax +55-55-3220-8034. E-mail: flores@ccr.ufsm.br

Received July 8, 2009. Accepted December 10, 2009. Available online December 18, 2009. Published February 1, 2010. 
at least 70 gene products (8). Alpha-herpesviruses (and other herpesviruses as well) encode a number of gene products that are non-essential for virus replication in tissue culture, although they are probably required for virus maintenance in nature $(7,11)$. Deletions of such genes have been used to study the role of individual proteins in virus replication in vitro and in vivo $(12,13)$ and for the production of recombinant strains for vaccine use $(14,15)$. The genes encoding the envelope glycoprotein $\mathrm{E}(\mathrm{gE})$ and the enzyme thymidine kinase (TK) are among the most frequent targets for deletion for vaccine production (16).

The envelope $\mathrm{gE}$ has been shown to be important for invasion and dissemination of BoHV-5 within the brain and for anterograde transport of BoHV-1 from the trigeminal ganglia to peripheral sites after reactivation $(12,17,18)$. Furthermore, deletion of the $\mathrm{gE}$ gene from the BoHV-1 and BoHV-5 genomes contributes to virus attenuation in calves and rabbits (16-18). In addition, the deletion of $\mathrm{gE}$ from vaccine strains provides an antigenic marker, which would allow serological differentiation of vaccinated from naturally infected animals (19). Vaccines with antigenic markers (also called DIVA vaccines, for differentiating infected from vaccinated animals) have constituted the basis for eradication of BoHV-1 and pseudorabies virus (PRV) from European countries and the USA (1) and are beginning to be used in South America (20).

The full expression of virulence of neurovirulent alpha-herpesviruses depends on the function of TK (12). Herpesvirus-encoded TK is an enzyme involved in the metabolism of deoxyribonucleotides (dNTPs), which is necessary for viral DNA synthesis and genome replication in non-dividing cells such as neurons $(12,21)$. Deletion of the TK gene in neurovirulent alpha-herpesviruses, namely human herpes simplex virus (HSV) and PRV, has been associated with deficient replication in neurons and reduced neurovirulence (22-25). For these reasons, BoHV-1 mutants lacking TK activity are also attenuated, albeit to a lesser extent $(16,26)$. For this reason, the TK gene has been an attractive target for gene deletion towards the production of attenuated strains for vaccine use (16).

Reactivation of latent infection by TK-defective alphaherpesviruses is also significantly impaired or even abolished, especially for HSV in mice $(22,23)$. On the other hand, attempts to reactivate latent infection by TK-negative BoHV-1 and PRV strains have yielded conflicting results, probably reflecting differences in the viruses, animals and experimental procedures (16,27-30). Despite these conflicting results, it is generally accepted that TK-defective alpha-herpesviruses replicate poorly (if so) in neurons and, therefore, are not expected to reactivate efficiently from latency.

The vaccines marketed in South America contain either inactivated or modified live BoHV-1 strains, none of them containing antigenic markers (31). Following the trend of European countries and predicting future sanitary restrictions for trading of animals and products, some South American countries are now embarking on the development and use of DIVA vaccines (20). Our group recently described the construction and in vitro characterization of three recombinants (BoHV-5gE $\Delta$, BoHV-5TK $\Delta$ and BoHV-5gE $\Delta$ TK $\Delta$ ) of a highly neurovirulent Brazilian BoHV-5 strain (31). Although these recombinants were constructed for vaccine purposes, they may also be useful for pathogenesis studies since they are defective in specific gene products involved in different stages of virus infection. The TK deletion, in particular, would provide an interesting means of attenuation for such neurovirulent agent.

The present article describes studies on the pathogenesis of acute and latent infections by these recombinants in a well-characterized rabbit model (32). Our results show that the recombinants BoHV-5TK $\Delta$ and BoHV-5gE $\Delta$ TK $\Delta$ are fully attenuated in rabbits upon intranasal inoculation and induce a virus-neutralizing antibody response. Although these recombinants retained the ability to establish latent infection, they did not reactivate readily upon dexamethasone (Dx) treatment. Thus, these results are promising regarding the use of these recombinants as vaccine strains, which, however, will depend on the presence of an equivalent phenotype in cattle.

\section{Material and Methods}

\section{Experimental design}

Groups of weanling rabbits were inoculated intranasally (in) with each BoHV-5 recombinant or the parental virus and submitted to clinical, virological and serological monitoring during acute infection. The identity of viruses shed in nasal secretions by the rabbits of each group was confirmed by PCR. Rabbits dying of neurological disease during acute infection had sections of their brains examined for infectivity. At day 42 post-infection (pi), rabbits were submitted to administration of $\mathrm{Dx}$ in order to reactivate latent infection and were monitored thereafter as described for acute infection. Twenty-eight days after Dx treatment, the rabbits were euthanized and brain sections [trigeminal ganglia (TG) and olfactory bulbs (OB)] were examined for viral DNA by PCR.

\section{Viruses and cells}

The Brazilian BoHV-5 strain SV507/99, isolated from a cow with neurological disease in southern Brazil and submitted to sequencing of the entire genome (8), was used as the parental virus to construct the recombinants. The construction and in vitro characterization of recombinants defective in the glycoprotein $\mathrm{E}$ (BoHV-5gE $\Delta$ ) or thymidine kinase (BoHV-5TK $\Delta$ ) gene or both genes (BoHV-5gE $\Delta$ TK $\Delta$ ) was described (31). The viruses were propagated in an MDBK-derived cell line named CRIB (ATCC-CRL 11883) maintained in minimum essential medium (Gibco, Brazil), supplemented with $10 \%$ fetal bovine serum (Cultilab, 
Brazil), $100 \mathrm{U} / \mathrm{mL}$ penicillin, and $100 \mu \mathrm{g} / \mathrm{mL}$ streptomycin (Nutricell, Brazil).

\section{In vitro growth kinetics}

Before rabbit inoculation, the recombinants were tested for their ability to replicate in rabbit kidney cells (RK-13; ATCC-CCL 37) in a one-step growth curve as described by Brum et al. (31). RK-13 cell monolayers were inoculated with each recombinant at a multiplicity of infection of 5 . At intervals after virus inoculation $(0,4,10,18$, and $24 \mathrm{~h}$ ), culture cells with supernatants were harvested and submitted to virus quantitation by limiting dilution. Virus titers were calculated by the method of Reed and Muench (33) and are reported as $\log _{10}$ median tissue culture infectious dose per milliliter ( $\left.\mathrm{TCID}_{50} / \mathrm{mL}\right)$.

\section{Animals, virus inoculation, monitoring and dexamethasone treatment}

Thirty-six New Zealand rabbits ( 28 to 30 days old) weighing $300-400 \mathrm{~g}$ were used for virus inoculation. The animals were randomly divided into four groups of 8 rabbits each plus a control group of 4 animals. Each group was maintained in a separate cage, without contact with each other, receiving water and food ad libitum. Rabbits of each experimental group were inoculated with one virus: parental SV507/99, gE negative (BoHV-5gE $\Delta$ ), TK-deleted (BoHV$5 T K \Delta$ ), and defective in both genes (BoHV- $5 \mathrm{gE} \Delta T K \Delta$ ). The inoculum consisted of supernatants of CRIB cells infected with each virus, containing approximately $10^{7.5}$ $\mathrm{TCID}_{50} / \mathrm{mL}$. The animals were inoculated in with $1 \mathrm{~mL}$ virus suspension into the paranasal sinuses $(0.5 \mathrm{~mL}$ in each side) through nephrine openings (34) after tranquilization with tiletamine/zolazepam (30 mg/kg intramuscular (im); Zoletil, Virbac, Brazil). Controls ( $\mathrm{N}=4)$ were inoculated in with culture medium.

Following virus inoculation, the rabbits were monitored twice a day for clinical signs. Nasal swabs for virus isolation were collected every two days up to day 14 pi (acute infection) and up to day 10 after Dx treatment (pDx). Swabs were vortexed and drained and the supernatant was inoculated into CRIB cell monolayers and submitted to three passages of 5 days each with the cultures being monitored for cytopathic effect. Pools of nasal secretions of each group were subsequently submitted to PCR to confirm the identity of the inoculated viruses. Rabbits developing severe neurological signs during acute infection were euthanized in extremis; brain sections were aseptically collected and tissue homogenates $(10 \% \mathrm{w} / \mathrm{v})$ were submitted to virus isolation in CRIB cells. Serum samples were collected at days 0 and 42 pi and submitted to a standard virus neutralizing (VN) assay for neutralizing antibodies, using 2-fold dilutions of sera against $100-200 \mathrm{TCID}_{50}$ of the parental virus (SV507/99), $2 \mathrm{~h}$ of incubation of the virus-serum mixture, and $72 \mathrm{~h}$ of incubation before a reading. CRIB cells were used as indicators of virus replication. Beginning at day 42 pi, the rabbits were submitted to 5 daily doses of Dx (2.6 $\mathrm{mg} \cdot \mathrm{kg}^{-1} \cdot \mathrm{day}^{-1}$, Decadronal, Achè, Brazil) by the im route. In the days following $D x$ administration, the animals were monitored as described for acute infection. Serum samples collected on the day of the first Dx administration (42 pi/0 $\mathrm{pDx}$ ) and 28 days later (day $28 \mathrm{pDx}$ ) were submitted to a $\mathrm{VN}$ assay as described above. At day $28 \mathrm{pDx}$, inoculated and control animals were euthanized and the $\mathrm{OB}$, brain and TGs were collected for detection of viral DNA by PCR.

All procedures of animal handling and experimentation were performed according to the recommendations of the Brazilian Committee on Animal Experimentation (COBEA; law \#6.638 of May 8, 1979). The animal experiments were approved by an Institutional Ethics and Animal Welfare Committee (Universidade Federal de Santa Maria, UFSM, approval \#44/2008; protocol \#23081.010078/2008-41).

\section{Identity of the viruses shed by inoculated rabbits}

In order to confirm the identity of each recombinant virus being shed by the respective groups, nasal secretions collected daily from the animals of each group were pooled and submitted to DNA extraction. Total DNA extracted from the secretions was submitted to PCR for the detection of TK and $\mathrm{gE}$ deletions. A PCR for the glycoprotein $\mathrm{B}$ gene was used as control (35). The presence, or absence, of the gE gene was detected using the following primers: forward 5'-ACGAG ACGTGCATCTTCC-3' (position 124.888 on the BoHV-5 genome) and reverse 5'-CAGCACGAAGACGTAGAG-3' (position 125.156), giving rise to a 269-bp product. The TK gene (or its absence) was detected by using the primers: forward 5'-GACGTCGTGACCCTCGTGTTTG-3' (position 64.971) and reverse 5'-TAGGAAGGCGCACGTGTTCG-3' (position 65.255), which amplify a 285-bp product. PCR was performed essentially as described by Brum et al. (31). Total DNA extracted from CRIB cells infected with BoHV-5TK $\Delta$ or BoHV-5gE $\Delta$ and SV507/99 was used as the negative and positive controls, respectively.

\section{DNA extraction from tissues and PCR}

Neural tissue collected on day $28 \mathrm{pDx}$ (TGs, OBs) were submitted to total DNA extraction using the DNAzol reagent (Invitrogen, USA). The extracted DNA was solubilized in Tris-EDTA buffer $(0.1-0.2 \mathrm{~mL})$ and stored at $-20^{\circ} \mathrm{C}$ until testing. DNA concentration was determined with a UV spectrophotometer at $260 \mathrm{~nm}$.

Total DNA was submitted to nested PCR using two sets of primers corresponding to positions 57.338 and 57.782 (primers 1 and 2) and 57.372 and 57.666 (primers 3 and 4) of the glycoprotein $B$ gene coding region of the BoHV-5 strain SV507 $(8,35)$. The external primers (primers 1 and 2 ) used in the first reaction were: forward 5'-CTCGAAAGCC GAGTACCTGCG-3' and reverse: 5'-CCAGTCCCAGG CAACCGTCAC-3'. The internal primers (primers 3 and 4) used in the second reaction were: forward 5'-GTGG TGGCCTTTGACCGCGAC-3' and reverse: 5'-GCTCCG 
GCGAGTAGCTGGTGTG-3'. The first PCR amplifies a 445-bp DNA fragment and the second results in a 295-bp amplicon. The PCR assays were performed in $25 \mu \mathrm{L}$, using $2 \mu \mathrm{L}$ template DNA (corresponding to approximately $1 \mu \mathrm{g}$ total DNA), $100 \mathrm{ng}$ of each primer, $2 \mathrm{mM} \mathrm{MgCl} 2,10 \mathrm{mM}$ dNTPs, $10 \%$ DMSO, $1 \mathrm{X}$ reaction buffer, and 2.5 units Taq DNA polymerase (Invitrogen, USA). The PCR conditions were: initial denaturation at $94^{\circ} \mathrm{C}$ for $5 \mathrm{~min}$, followed by 35 cycles at $94^{\circ} \mathrm{C}$ for $45 \mathrm{~s}$ for DNA denaturation, at $56^{\circ} \mathrm{C}$ for $45 \mathrm{~s}$ for primer annealing and at $72^{\circ} \mathrm{C}$ for $45 \mathrm{~s}$ for primer extension, and a final extension at $72^{\circ} \mathrm{C}$ for $10 \mathrm{~min}$. Total DNA extracted from the brain of a control non-infected rabbit and from a rabbit with acute BoHV-5 infection was used as negative and positive controls, respectively. PCR products were analyzed under UV light after electrophoresis on $1.5 \%$ agarose gel stained with ethidium bromide. To determine

Table 1. Virological, clinical and serological findings during acute infection of rabbits inoculated with the parental virus and recombinants of bovine herpesvirus 5 (BoHV-5).

\begin{tabular}{|c|c|c|c|c|}
\hline Strain & Animal & Viral sheddinga (day pi) & Neurological disease (day pi) & VN antibodies ${ }^{b}$ (42 pi) \\
\hline \multirow[t]{8}{*}{ SV507/99 } & 1 & $2-8$ & $+(8)^{c}$ & nt \\
\hline & 2 & $2-8$ & $+(8)$ & $\mathrm{nt}$ \\
\hline & 3 & $2-6$ & $+(13)$ & $\mathrm{nt}$ \\
\hline & 4 & $2-6$ & $+(13)$ & nt \\
\hline & 5 & $2-6$ & $+(7)$ & nt \\
\hline & 6 & $2-6$ & $+(8)$ & nt \\
\hline & 7 & $2-8$ & $+(10)$ & $\mathrm{nt}$ \\
\hline & 8 & $2-8$ & $+(9)$ & nt \\
\hline \multirow[t]{8}{*}{$\mathrm{gE} \Delta$} & 1 & $2-4$ & $+(15)$ & $\mathrm{nt}$ \\
\hline & 2 & $2-6$ & $+(10)$ & $\mathrm{nt}$ \\
\hline & 3 & $2-6$ & - & 256 \\
\hline & 4 & $2-8$ & - & 256 \\
\hline & 5 & $4-6$ & - & 256 \\
\hline & 6 & $2-6$ & - & 32 \\
\hline & 7 & - & $+(10)$ & $\mathrm{nt}$ \\
\hline & 8 & $4-8$ & - & 8 \\
\hline \multirow[t]{8}{*}{$\mathrm{TK} \Delta$} & 1 & - & & 32 \\
\hline & 2 & 8 & & 64 \\
\hline & 3 & 6 & & 16 \\
\hline & 4 & - & & 32 \\
\hline & 5 & $4-8$ & & 64 \\
\hline & 6 & $4-8$ & & 32 \\
\hline & 7 & 4 & & 32 \\
\hline & 8 & $2-10$ & & 2 \\
\hline \multirow[t]{8}{*}{$\mathrm{gE} \Delta \mathrm{TK} \Delta$} & 1 & 6 & - & 2 \\
\hline & 2 & 4 & - & 2 \\
\hline & 3 & - & - & 16 \\
\hline & 4 & - & - & 16 \\
\hline & 5 & 6 & - & 8 \\
\hline & 6 & - & - & 2 \\
\hline & 7 & - & - & 4 \\
\hline & 8 & - & - & 32 \\
\hline
\end{tabular}

aperiod of virus shedding in nasal secretions; bVN titers reported as the reciprocal of the highest serum dilution capable of preventing virus replication; ${ }^{c}$ day post-inoculation (pi) on which the animals died or were submitted to euthanasia; "+" = development of neurological signs; "-" = absence of virus shedding or neurological signs; $\mathrm{nt}=$ not tested. 
the sensitivity of the PCR, 10-fold dilutions of strain SV-507 DNA were prepared with DNA $(1 \mu \mathrm{g} / \mu \mathrm{L})$ extracted from the brain of a BoHV-5-seronegative cow and used as templates for PCR. Based on the average size of the BHV-5 genome (137 kb), an estimate of the number of genome copies detected in the PCR was calculated (18).

\section{Results}

\section{Kinetics of virus replication in rabbit cells}

Since the recombinants were amplified and characterized in bovine cells (MDBK) and BoHV- $5 g E \Delta$ and BoHV$5 \mathrm{gE} \Delta \mathrm{TK} \Delta$ produced slightly smaller plaques, before inoculation into rabbits we investigated their ability to replicate in cultured rabbit cells. A one-step growth curve experiment performed in RK-13 cells demonstrated that the recombinants BoHV-5TK $\Delta$ and BoHV-5gE $\Delta$ replicated with similar kinetics and at equivalent titers to those of the parental virus in rabbit cells (data not shown). The double deletion mutant (BoHV-5gE $\Delta$ TK $\Delta$ ) replicated with a slightly lower kinetics and to a lower titer. In a previous experiment on MDBK cells, the three recombinants were shown to retain their ability to replicate with about the same efficiency as the parental virus (31). Thus, a possible impairment of in vivo replication in rabbits would not be attributable to a gross defect in replication in rabbit cells.

\section{Animal experiment - acute infection}

All rabbits inoculated with the parental virus SV507/99 shed virus in nasal secretions between days 2 and 8 pi and developed typical neurological signs (Table 1). The neurological disease started between days 7 and 13 pi, depending on the animal, and was characterized by depression/excitation, ptyalism, bruxism, opisthotonus, seizures, and blindness in some cases. Animals showing severe neurological signs were euthanized.

Rabbits inoculated with the recombinant BoHV-5gE $\Delta$ shed virus between days 2 and 8 , and 3 of them (\#1, 2, and 7) developed neurological signs similar to those of the rabbits inoculated with the parental virus. These rabbits were euthanized in extremis at days 10 and $15 \mathrm{pi}$. Infectious virus was not recovered from nasal swabs collected from rabbit \#7, but infectivity was detected in several areas of the brain of this animal (Table 2). The rabbits surviving acute infection developed VN titers from 8 to 256 at day 42 pi.

The group inoculated with the recombinant BoHV-5TK $\Delta$ remained healthy throughout acute infection. Virus shedding was detected in 6/8 rabbits and lasted one to eight days (Table 1). These rabbits, including those in which virus shedding was not detected (\#1 and 4), developed VN titers of 2 to 64 in sera collected at day $42 \mathrm{pi}$, indicating that they were efficiently infected.

None of the rabbits inoculated with the double mutant (BoHV-5gE $\Delta$ TK $\Delta$ ) developed clinical signs during the period of monitoring. Virus shedding in swabs collected every two days was detected in 3 of 8 animals. All inoculated animals seroconverted by day 42 pi (titers ranging from 2 to 32), indicating that virus replication took place.

These results show that the recombinants BoHV-5TK $\Delta$ and BoHV-5gE $\Delta \mathrm{TK} \Delta$ were fully attenuated in rabbits upon in inoculation. Apparently, these viruses (especially the double mutant) replicated with a lower efficiency in the nasal

Table 2. Distribution of infectivity in the brain of rabbits inoculated with the parental virus or with the recombinant BoHV$5 \mathrm{gE} \Delta$.

\begin{tabular}{|c|c|c|c|c|c|c|c|c|c|c|c|}
\hline \multirow[t]{2}{*}{ Virus } & \multirow[t]{2}{*}{ Animal } & \multicolumn{10}{|c|}{ Brain area } \\
\hline & & $\mathrm{OB} / \mathrm{OC}$ & $A C$ & VLC & DLC & $\mathrm{PC}$ & Th & TG & $\mathrm{MO}$ & $\mathrm{PO}$ & $\mathrm{MB}$ \\
\hline \multirow[t]{8}{*}{ SV507/99 } & 1 & + & + & + & + & + & + & - & + & + & + \\
\hline & 2 & + & + & + & - & - & - & - & - & + & - \\
\hline & 3 & + & - & + & - & - & + & - & - & - & - \\
\hline & 4 & - & + & + & + & + & - & - & + & - & + \\
\hline & 5 & + & + & + & - & + & + & - & + & - & + \\
\hline & 6 & - & + & - & + & - & + & - & - & + & + \\
\hline & 7 & - & - & + & - & - & - & - & - & - & - \\
\hline & 8 & + & + & + & + & + & + & - & + & + & + \\
\hline \multirow[t]{3}{*}{$\mathrm{gE} \Delta$} & 1 & - & - & + & - & - & - & - & - & - & - \\
\hline & 2 & + & + & + & + & + & + & - & - & - & - \\
\hline & 7 & + & + & + & + & + & + & - & - & - & - \\
\hline
\end{tabular}

$\mathrm{OB} / \mathrm{OC}=$ olfactory bulb/olfactory cortex; $\mathrm{AC}=$ anterior cortex; $\mathrm{VLC}=$ ventrolateral cortex; $\mathrm{DLC}=$ dorsolateral cortex; $\mathrm{PC}$ = posterior cortex; $\mathrm{Th}=$ thalamus; $\mathrm{TG}=$ trigeminal ganglia; $\mathrm{MO}=$ medulla oblongata; $\mathrm{PO}=$ pons; $\mathrm{MB}=$ midbrain. "+" and "-" indicate positive and negative for infectivity, respectively. 
mucosa. Nevertheless, serology data demonstrated that the viruses replicated in all animals at sufficient levels to stimulate the immune response. In contrast, the recombinant BoHV-5gE $\Delta$ retained part of its neurovirulence, producing neurological disease in 3 of 8 rabbits. The duration of virus shedding by this recombinant in most animals was similar to that of the parental virus and virus replication resulted in moderate to high VN titers (Table 1).

\section{Confirmation of the identity of the virus shed by inoculated rabbits}

The experimental groups were maintained in separate cages without direct or indirect contact between them to avoid possible cross-infection. Nonetheless, in order to confirm the identity of each recombinant virus being shed by each group, nasal secretions collected daily from the animals of each group were pooled, submitted to DNA extraction and to a specific PCR designed to detect deletion of each gene and of both genes (31). This procedure was repeated from day 2 to day $8 \mathrm{pi}$, the period of virus shedding by most animals. A representative result of these PCRs is shown in Figure 1. Nasal secretions of parental,
SV507/99 strain-inoculated rabbits contained virus with both genes deleted; individual ( $\mathrm{gE} \Delta, \mathrm{TK} \Delta$ ) and double deletions ( $\mathrm{gE} \Delta \mathrm{TK} \Delta$ ) were detected in nasal secretions collected from the respective groups. These results show that each group excreted the appropriate virus and ruled out any possible cross-infection between groups.

\section{Distribution of parental virus and recombinant BoHV-5gE $\Delta$ in the brain}

Three of 8 rabbits inoculated with the recombinant BoHV-5gE $\Delta$ developed neurological disease clinically indistinguishable from that developed by rabbits inoculated with the parental virus. In order to determine the extent of dissemination and distribution of each virus, brain sections of rabbits from both groups (SV507/99 and BoHV-5gE $\Delta$ ) were submitted to virus isolation. As shown in Table 2, the parental virus was more widely distributed in the brain than the recombinant virus. It reached deeper areas of the brain, considering the olfactory pathway of virus invasion, being detected in all frontal structures, cortices, thalamus and also in the brain stem. In contrast, the recombinant virus was detected in the anterior and median sections and barely reached the posterior areas. These results demonstrate that the recombinant BoHV-5gE $\Delta$ invaded and replicated within the brain but showed a relatively restricted distribution compared to the parental virus.
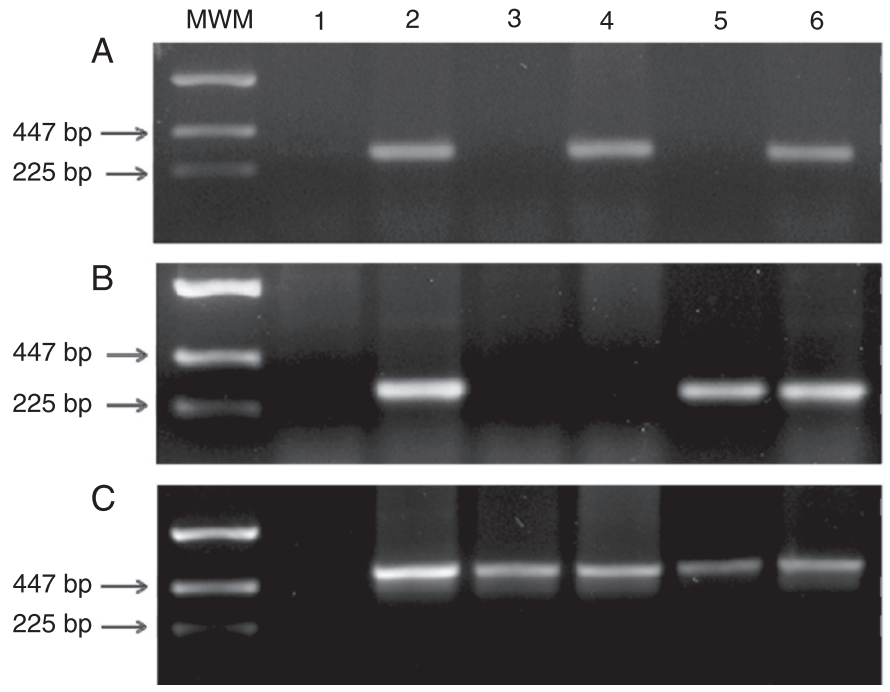

Figure 1. Typical results of a PCR performed to confirm the identity of viruses shed in nasal secretions by rabbits of the respective groups. $A$, PCR for the TK gene (285 bp). B, PCR for the glycoprotein E gene (269 bp). C, PCR for the glycoprotein B gene (control; $445 \mathrm{bp}$ ). MWM = molecular weight marker. Lane 1, Negative control (DNA template from the brain of a BoHV-5-seronegative cow); lane 2, positive control, DNA extracted from the supernatant of CRIB cells infected with the parental virus; lane 3, pool of nasal secretions of rabbits inoculated with the double mutant BoHV-5gE $\Delta \mathrm{TK} \Delta$; lane 4, nasal secretions of rabbits inoculated with the recombinant BoHV- $5 \mathrm{gE} \Delta$; lane 5 , nasal secretions of rabbits inoculated with the recombinant BoHV-5TK $\Delta$; lane 6 , nasal secretions of rabbits inoculated with the parental virus (SV507/99). Ethidium bromidestained $1.5 \%$ agarose gel; the sizes of the corresponding markers are indicated.

\section{Latent infection - attempt to reactivate and molecular detection}

On day $42 \mathrm{pi}$, all rabbits that survived the acute infection with the recombinants BoHV- $5 \mathrm{gE} \Delta(\mathrm{N}=5)$, BoHV-5TK $\Delta(\mathrm{N}=8)$ and BoHV-5gE $\Delta \mathrm{TK} \Delta(\mathrm{N}=8)$ were submitted to Dx treatment in an attempt to reactivate a putative latent infection. On that day, all inoculated animals had VN antibody titers ranging from 2 to 256 , indicating that they harbored virus replication in the nose during acute infection. However, 5 daily administrations of Dx to these animals did not result in detectable virus shedding or in an increase in VN titers (Table 3). Likewise, none of the animals showed clinical signs indicative of clinical recrudescence. Thus, these results demonstrate that the recombinants were not reactivated upon Dx treatment. Since all rabbits inoculated with the parental virus died during acute infection, reactivation attempts were not possible. Nevertheless, previous studies have achieved virus reactivation by $D x$ treatment ranging from 56.8 to $100 \%$ in BoHV-5-inoculated rabbits, even those inoculated with relatively low virus titers $\left(10^{6.5-7.0}\right.$ TCID $\left._{50}\right)(36,37)$.

The BoHV-5TK $\Delta$ recombinant and, to a lesser extent, the BoHV-5gE $\Delta$ TK $\Delta$ virus, replicated with an apparent low efficiency in the nose during acute infection, in spite of the VN titers developed by these 
Table 3. Findings after dexamethasone (Dx) administration in rabbits inoculated with the parental virus and recombinants of bovine herpesvirus 5 (BoHV-5).

\begin{tabular}{|c|c|c|c|c|c|c|c|}
\hline \multirow[t]{2}{*}{ Strain } & \multirow[t]{2}{*}{ Animal } & \multirow[t]{2}{*}{ Viral shedding $(p D x)$} & \multirow[t]{2}{*}{ Neurological disease } & \multicolumn{2}{|c|}{ Viral neutralizing antibodies ${ }^{a}$} & \multicolumn{2}{|c|}{ Viral DNA (28 pDx) } \\
\hline & & & & $42 \mathrm{pi} / 0 \mathrm{pDx}$ & $28 \mathrm{pDx}$ & TG & $\mathrm{OB}$ \\
\hline \multirow[t]{5}{*}{$\mathrm{gE} \Delta$} & 3 & - & - & $>256$ & $>256$ & + & nt \\
\hline & 4 & - & - & $>256$ & 64 & + & nt \\
\hline & 5 & - & - & $>256$ & 128 & + & nt \\
\hline & 6 & - & - & 32 & 16 & + & nt \\
\hline & 8 & - & - & 8 & 2 & + & nt \\
\hline \multirow[t]{8}{*}{$\mathrm{TK} \Delta$} & 1 & - & - & 32 & 64 & + & $\mathrm{nt}$ \\
\hline & 2 & - & - & 64 & 32 & + & nt \\
\hline & 3 & - & - & 16 & 32 & + & nt \\
\hline & 4 & - & - & 32 & 8 & + & nt \\
\hline & 5 & - & - & 64 & 4 & + & $\mathrm{nt}$ \\
\hline & 6 & - & - & 32 & 4 & + & nt \\
\hline & 7 & - & - & 32 & 16 & + & $\mathrm{nt}$ \\
\hline & 8 & - & - & 2 & 2 & + & $\mathrm{nt}$ \\
\hline \multirow[t]{7}{*}{$\mathrm{gE} \Delta \mathrm{TK} \Delta$} & 2 & - & - & 2 & - & - & + \\
\hline & 3 & - & - & 16 & 2 & - & + \\
\hline & 4 & - & - & 16 & 2 & - & + \\
\hline & 5 & - & - & 8 & 2 & - & + \\
\hline & 6 & - & - & 2 & 2 & - & + \\
\hline & 7 & - & - & 4 & - & + & $\mathrm{nt}$ \\
\hline & 8 & - & - & 32 & 2 & - & + \\
\hline
\end{tabular}

aViral neutralizing antibody titers are reported as the reciprocal of the highest serum dilution capable of preventing virus replication. $\mathrm{pDx}=$ post-dexamethasone administration; $\mathrm{pi}=$ post-inoculation; $\mathrm{TG}=$ trigeminal ganglia; $\mathrm{OB}=$ olfactory bulb (tested only in animals whose TG were negative for viral DNA by PCR); "-" = negative in the respective test; "+" = positive for viral DNA by PCR; $\mathrm{nt}=$ not tested.

animals at day $42 \mathrm{pi}$, and were not reactivated upon Dx treatment. Thus, we argued whether acute replication by these viruses, and by recombinant BoHV-5gE $\Delta$ as well, was sufficient to assure the establishment of latency. Next, a nested PCR (the test sensitivity was estimated to be approximately 10 to 100 genome copies per reaction) performed on total DNA extracted from the TGs of rabbits from groups inoculated with each single mutant $(\mathrm{gE} \Delta$ and $\mathrm{TK} \Delta$ ) confirmed that they all harbored latent viral DNA, albeit it failed to detect viral DNA in the TGs of 7 of 8 rabbits of the group inoculated with the double mutant (Table 3). A second round of PCR was then performed on total DNA extracted from the OB of this last group. This PCR confirmed the presence of latent viral DNA in the OB of all rabbits inoculated with the double mutant (Table 3). Previous studies have demonstrated the presence of BoHV-5 latent DNA in the OBs of experimentally infected calves (9) and rabbits (36). Taken together, these results show that all three recombinants were able to establish latent infection in the TGs and/or in the OB of inoculated rabbits, yet they were not reactivated by $D x$ treatment.

\section{Discussion}

We investigated the virulence of three BoHV-5 recombinants in rabbits. The recombinants defective in $\mathrm{gE}$ (BoHV-5gE $\Delta$ ), enzyme TK (BoHV-5TK $\Delta$ ) and both TK and $\mathrm{gE}(\mathrm{BoHV}-5 \mathrm{gE} \Delta \mathrm{TK} \Delta$ ) were constructed from a neurovirulent Brazilian BoHV-5 strain (SV507/99) as part of a strategy to produce an attenuated, differential vaccine for use in South America. The recombinant BoHV-5TK $\Delta$ and the double deletion mutant (BoHV-5gE $\Delta \mathrm{TK} \Delta$ ) were fully attenuated for rabbits after in inoculation. Although these viruses, especially the double mutant, replicated less efficiently than the parental virus in the nasal cavity, they were able to induce a VN antibody response in the inoculated rabbits. In contrast, the recombinant defective in $\mathrm{gE}(\mathrm{BoHV}-5 \mathrm{gE} \Delta)$ partially retained its neurovirulence for rabbits. All three recombinants 
conserved their ability to establish latent infection in neural tissues (TGs and/or OBs) although they were not capable of reactivating from latency upon Dx administration. These results open the way for further testing of the recombinants $\mathrm{BoHV}-5 \mathrm{TK} \Delta$ and BoHV-5gE $\Delta \mathrm{TK} \Delta$ in cattle for the potential use of these viruses as vaccine strains. These recombinants may also be useful to study the role of each deleted gene product in the biology of BoHV-5 infection and its interaction with the host.

The pathogenesis of BoHV-5 neurological disease in cattle is still poorly understood and several aspects of acute and latent infection have been studied in a rabbit model $(32,34)$. The neurological infection involves an initial viral replication at the site of entry (nasal epithelium) and axonal transport to and replication in second-, third- and fourth-order neurons in several areas of the brain (38). Regardless of the biological and molecular mechanisms underlying the development of neurological disease, which are merely hypothetical at this time, massive virus replication in several areas of the brain is a consistent finding during acute BoHV5 infection in rabbits and calves $(34,38,39)$. Thus, the full expression of BoHV-5 neurovirulence likely depends upon the ability of the virus to reach the brain from peripheral sites (neuroinvasiveness) and to replicate to high titers in neuronal cells (neurogrowth).

Based on pathogenesis studies with other neuropathogenic alpha-herpesviruses (HSV, PRV, BoHV-1, as well as BoHV-5), the envelope $\mathrm{gE}$ plays an important role in virus transport along circuits of synaptically connected neurons and, consequently, influences viral invasion of the brain (17). gE-defective BoHV-5 strains show reduced neuroinvasiveness and neurovirulence in rabbits (17), while a BoHV-1 gEnegative recombinant is poorly transported anterogradely from the TGs to the nose after virus reactivation $(18,40)$. Deletion of $\mathrm{gE}$ in BoHV-1 strains is associated with significant, although partial, attenuation in calves and has also been used as the antigenic marker in differential vaccines (16). Our recombinant BoHV-5gE $\Delta$ replicated efficiently in the nose and was partially neurovirulent for rabbits, producing neurological disease in $3 / 8$ animals. Although the recombinant was less widely distributed in the brain than the parental virus, it was able to reach and replicate in the anterior areas of the CNS. A similar phenotype has been observed for other BoHV-5 gE-negative recombinants (17). Virus replication in these anterior areas has been implicated in the production of seizures, a hallmark of BoHV-5 neurological infection (38). Thus, gE deletion in the SV507/99 strain reduced the virulence but was not sufficient to abolish the ability of the virus to invade and replicate in the brain of rabbits, producing neurological disease. This recombinant established latent infection in the TG/OB although it was not reactivated upon Dx treatment. The lack of excretion of this virus after Dx treatment, taken as indicative of virus reactivation, may be related to deficient anterograde axonal transport as demonstrated for a gE-negative BoHV-1 strain in calves $(18,40)$. Alternatively, this virus was not reactivated in the ganglia by corticosteroid treatment. Further studies will determine the impact of $\mathrm{gE}$ deletion on the phenotype of this virus in cattle and whether a single $\mathrm{gE}$ mutant is sufficiently attenuated for use as a live vaccine.

The alpha-herpesvirus TK is an enzyme involved in the metabolism of dNTPs and is absolutely necessary for efficient viral replication in non-dividing cells such as neurons (28). Consequently, TK activity is required for efficient replication in neurons during acute infection and reactivation from latency but is not necessary for virus replication in epithelial cells or in cell culture. PRV, HSV and, to a lesser extent, BoHV-1 defective in the TK gene product display reduced virulence and a relative inability to reactivate from latent infection $(12,25,28,30)$. Since BoHV-5 neuropathogenesis is associated with virus replication and dissemination within the brain, we assumed that functional TK would be necessary for the full expression of virus neurovirulence in vivo. Our results confirmed this prediction: deletion of the TK gene in SV507/99 resulted in a dramatic reduction in neurovirulence for rabbits. In a previous study, our group reported the production of a brivudin-resistant BoHV-5 variant, probably defective in TK activity, that displayed a similar attenuated phenotype in rabbits (31). Studies to determine whether these mutants are impaired in invasion, dissemination or productive replication in the brain are underway and may shed light on the exact role of TK in the biology of BoHV-5 and the effects of its deletion on the viral phenotype. Thus, our BoHV-5TK $\Delta$ recombinant was shown to be fully attenuated for rabbits after in inoculation and it would be worthwhile to investigate whether it presents the same phenotype in cattle.

On the other hand, a search for BoHV-5TK $\Delta$ DNA by PCR at day $28 \mathrm{pDx}$ demonstrated the presence of latent viral DNA in TGs, demonstrating that the recombinant virus was capable of reaching these sites during acute infection. However, the TK-negative virus was not reactivated from latent infection, confirming findings observed for other TK-defective alpha-herpesviruses $(22,23,25)$. The lack of reactivation by TK-defective alpha-herpesvirus is probably related to their inability to replicate productively in neurons, a condition necessary for virus reactivation and excretion (21).

The double deletion mutant BoHV-5gE $\Delta \mathrm{TK} \Delta$ was also fully attenuated for rabbits. The replication of this recombinant in the nose was noticeably reduced, a fact that could partially explain its inability to produce neurological disease. Nevertheless, the relatively low replication levels in the nose did not abolish the ability of the virus to induce a VN response. Whether this magnitude of $\mathrm{VN}$ response would protect upon challenge is not known and would deserve investigation. Virus replication at the site of entry also sufficed to assure virus transport to the OB and/or TGs where latent infection was established. Again, as demonstrated for the other two recombinants, the double mutant was not 
capable of reactivating the latent infection, probably reflecting a combined deleterious effect of the lack of both TK and $\mathrm{gE}$. Thus, this recombinant would be a candidate for use as an attenuated, antigenically marked vaccine strain for cattle. Subsequent studies are needed to determine the replication efficiency, attenuation and immunogenicity of this recombinant in cattle.

The BoHV-5 recombinants defective in TK alone or in combination with $\mathrm{gE}$ are attenuated for rabbits and constitute potential vaccine candidates, depending upon the confirmation of this phenotype in cattle. The single mutant $\mathrm{gE}$ retained part of its virulence for rabbits; however, its phenotype awaits confirmation in cattle. Regardless of their potential use in vaccine formulations, the recombinants may

\section{References}

1. Engels M, Ackermann M. Pathogenesis of ruminant herpesvirus infections. Vet Microbiol 1996; 53: 3-15.

2. Silva MS, Brum MC, Loreto EL, Weiblen R, Flores EF. Molecular and antigenic characterization of Brazilian bovine herpesvirus type 1 isolates recovered from the brain of cattle with neurological disease. Virus Res 2007; 129: 191-199.

3. Silva MS, Brum MCS, Weiblen R, Flores EF. Identificação e diferenciação de herpesvírus bovino tipos 1 e 5 isolados de amostras clínicas no Centro-Sul do Brasil, Argentina e Uruguai (1987-2006). Pesqui Vet Bras 2007; 27: 403-408.

4. Carrillo BJ, Ambrogi A, Schudel AA, Vazquez M, Dahme E, Pospischil A. Meningoencephalitis caused by IBR virus in calves in Argentina. Zentralb/ Veterinarmed B 1983; 30: 327-332.

5. d'Offay JM, Ely RW, Baldwin CA, Whitenack DL, Stair EL, Collins JK. Diagnosis of encephalitic bovine herpesvirus type 5 (BHV-5) infection in cattle: virus isolation and immunohistochemical detection of antigen in formalin-fixed bovine brain tissues. J Vet Diagn Invest 1995; 7: 247-251.

6. Engels M, Giuliani C, Wild P, Beck TM, Loepfe E, Wyler R. The genome of bovine herpesvirus 1 (BHV-1) strains exhibiting a neuropathogenic potential compared to known BHV-1 strains by restriction site mapping and cross-hybridization. Virus Res 1986; 6: 57-73.

7. Roizmann B, Desrosiers RC, Fleckenstein B, Lopez C, Minson AC, Studdert MJ. The family Herpesviridae: an update. The Herpesvirus Study Group of the International Committee on Taxonomy of Viruses. Arch Virol 1992; 123: 425-449.

8. Delhon G, Moraes MP, Lu Z, Afonso CL, Flores EF, Weiblen $\mathrm{R}$, et al. Genome of bovine herpesvirus 5. J Virol 2003; 77: 10339-10347.

9. Vogel FS, Caron L, Flores EF, Weiblen R, Winkelmann ER, Mayer SV, et al. Distribution of bovine herpesvirus type 5 DNA in the central nervous systems of latently, experimentally infected calves. J Clin Microbiol 2003; 41: 4512-4520.

10. Rock DL. Latent infection with bovine herpesvirus type-1. Semin Virol 1994; 5: 233-240.

11. Schwyzer M, Ackermann M. Molecular virology of ruminant herpesviruses. Vet Microbiol 1996; 53: 17-29.

12. Enquist LW, Husak PJ, Banfield BW, Smith GA. Infection represent useful tools to study the function of each gene product in the biology of BoHV-5 infection.

\section{Acknowledgments}

S.C. da Silva is the recipient of a Master's fellowship from CAPES. M.C.S. Brum was the recipient of doctoral fellowships from CNPq and CAPES (PDEE/UFSM). E.F. Flores (\#301666/04-0) and R. Weiblen (\#301339/04-0) are recipients of CNPq fellowships. The project was developed in collaboration with S.I. Chowdhury, Kansas State University, Manhattan, KS, USA, and funded by PRONEX, FAPERGS, CNPq and CAPES. and spread of alphaherpesviruses in the nervous system. Adv Virus Res 1998; 51: 237-347.

13. Mettenleiter TC. Pathogenesis of neurotropic herpesviruses: role of viral glycoproteins in neuroinvasion and transneuronal spread. Virus Res 2003; 92: 197-206.

14. Belknap EB, Walters LM, Kelling C, Ayers VK, Norris J, McMillen $\mathrm{J}$, et al. Immunogenicity and protective efficacy of a gE, gG and US2 gene-deleted bovine herpesvirus-1 (BHV-1) vaccine. Vaccine 1999; 17: 2297-2305.

15. Flores EF, Osorio FA, Zanella EL, Kit S, Kit M. Efficacy of a deletion mutant bovine herpesvirus-1 (BHV-1) vaccine that allows serologic differentiation of vaccinated from naturally infected animals. J Vet Diagn Invest 1993; 5: 534-540.

16. Kaashoek MJ, van Engelenburg FA, Moerman A, Gielkens $A L$, Rijsewijk FA, van Oirschot JT. Virulence and immunogenicity in calves of thymidine kinase- and glycoprotein Enegative bovine herpesvirus 1 mutants. Vet Microbiol 1996; 48: $143-153$

17. Chowdhury SI, Lee BJ, Ozkul A, Weiss ML. Bovine herpesvirus 5 glycoprotein $E$ is important for neuroinvasiveness and neurovirulence in the olfactory pathway of the rabbit. $J$ Virol 2000; 74: 2094-2106.

18. Liu ZF, Brum MC, Doster A, Jones C, Chowdhury SI. A bovine herpesvirus type 1 mutant virus specifying a carboxylterminal truncation of glycoprotein $\mathrm{E}$ is defective in anterograde neuronal transport in rabbits and calves. J Virol 2008; 82: 7432-7442.

19. van Oirschot JT, Kaashoek MJ, Rijsewijk FA, Stegeman JA. The use of marker vaccines in eradication of herpesviruses. J Biotechnol 1996; 44: 75-81.

20. Franco AC, Hübner SdO, Oliveira APd, Batista HBdCR, Roehe PM, Rijsewijk FAM. Construction and characterization of a bovine herpesvirus 5 mutant with a deletion of the $\mathrm{gl}, \mathrm{gE}$ and US9 genes. Braz J Microbiol 2007; 38: 667-673.

21. Tikoo SK, Campos M, Babiuk LA. Bovine herpesvirus 1 (BHV-1): biology, pathogenesis, and control. Adv Virus Res 1995; 45: 191-223.

22. Coen DM, Kosz-Vnenchak M, Jacobson JG, Leib DA, Bogard CL, Schaffer PA, et al. Thymidine kinase-negative herpes simplex virus mutants establish latency in mouse trigeminal ganglia but do not reactivate. Proc Natl Acad Sci 
U S A 1989; 86: 4736-4740.

23. Chen SH, Pearson A, Coen DM, Chen SH. Failure of thymidine kinase-negative herpes simplex virus to reactivate from latency following efficient establishment. J Virol 2004; 78: $520-523$.

24. Moormann RJ, de Rover T, Briaire J, Peeters BP, Gielkens $A L$, van Oirschot JT. Inactivation of the thymidine kinase gene of a gl deletion mutant of pseudorabies virus generates a safe but still highly immunogenic vaccine strain. J Gen Virol 1990; 71 (Part 7): 1591-1595.

25. Ferrari M, Mettenleiter TC, Romanelli MG, Cabassi E, Corradi $A$, Dal Mas $N$, et al. A comparative study of pseudorabies virus (PRV) strains with defects in thymidine kinase and glycoprotein genes. J Comp Pathol 2000; 123: 152-163.

26. Kit S, Qavi H, Gaines JD, Billingsley P, McConnell S. Thymidine kinase-negative bovine herpesvirus type 1 mutant is stable and highly attenuated in calves. Arch Virol 1985; 86: 63-83.

27. Gilliam SE, Thackray AM, Brown GA, Field HJ. The pathogenesis of wild type and drug resistant mutant strains of bovine herpesvirus-1 (BHV-1) in the natural host. Arch Virol 1993; 128: 43-54.

28. Whetstone CA, Miller JM, Seal BS, Bello LJ, Lawrence WC. Latency and reactivation of a thymidine kinase-negative bovine herpesvirus 1 deletion mutant. Arch Virol 1992; 122 : 207-214.

29. Mengeling WL. Virus reactivation in pigs latently infected with a thymidine kinase negative vaccine strain of pseudorabies virus. Arch Virol 1991; 120: 57-70.

30. Chowdhury SI. Construction and characterization of an attenuated bovine herpesvirus type 1 (BHV-1) recombinant virus. Vet Microbiol 1996; 52: 13-23.

31. Brum MSC, Weiblen R, Flores EF, Chowdhury SI. Construction and growth properties of bovine herpesvirus type 5 recombinants defective in the glycoprotein $\mathrm{E}$ or thymidine kinase gene or both. Braz J Med Biol Res 2010; 43: 217224.
32. Chowdhury SI, Lee BJ, Mosier D, Sur JH, Osorio FA, Kennedy $G$, et al. Neuropathology of bovine herpesvirus type 5 (BHV-5) meningo-encephalitis in a rabbit seizure model. $J$ Comp Pathol 1997; 117: 295-310.

33. Reed LJ, Muench H. A simple method for estimating fifty per cent end points. Am J Hyg 1938; 27: 493-497.

34. Silva AMd, Flores EF, Weiblen R, Canto MC, Irigoyen LF, Roehe PM, et al. Pathogenesis of meningoencephalitis in rabbits by bovine herpesvirus type-5 (BHV-5). Braz J Microbiol 1999; 30: 22-31.

35. Diel DG, Almeida SR, Brum MC, Dezengrini R, Weiblen R, Flores EF. Acute and latent infection by bovine herpesvirus type 5 in experimentally infected goats. Vet Microbiol 2007; 121: 257-267.

36. Mayer SV, Quadros VL, Vogel FS, Winkelmann ER, Arenhart $S$, Weiblen $R$, et al. Dexamethasone-induced reactivation of bovine herpesvirus type 5 latent infection in experimentally infected rabbits results in a broader distribution of latent viral DNA in the brain. Braz J Med Biol Res 2006; 39: 335-343.

37. Caron L, Flores EF, Weiblen R, Scherer CF, Irigoyen LF, Roehe PM, et al. Latent infection by bovine herpesvirus type-5 in experimentally infected rabbits: virus reactivation, shedding and recrudescence of neurological disease. Vet Microbiol 2002; 84: 285-295.

38. Lee BJ, Weiss ML, Mosier D, Chowdhury SI. Spread of bovine herpesvirus type 5 (BHV-5) in the rabbit brain after intranasal inoculation. J Neurovirol 1999; 5: 474-484.

39. Dezengrini R, Weiss M, Torres FD, Oliveira MS, Furian F, Mello CF, et al. Bovine herpesvirus 5 induces an overproduction of nitric oxide in the brain of rabbits that correlates with virus dissemination and precedes the development of neurological signs. J Neurovirol 2009; 15: 153-163.

40. Brum MC, Coats C, Sangena RB, Doster A, Jones C, Chowdhury SI. Bovine herpesvirus type 1 (BoHV-1) anterograde neuronal transport from trigeminal ganglia to nose and eye requires glycoprotein E. J Neurovirol 2009; 15: 196-201. 